\title{
RANGGAWARSITA DAN SUFISME JAWA: STUDI PEMIKIRAN BAGUS BURHAM TERHADAP BUDAYA ISLAM JAWA (1823- 1870)
}

\author{
Samudra Eka Cipta \\ Fakultas Pendidikan Ilmu Pengetahuan Sosial, Universitas Pendidikan Indonesia \\ samudra.eka@student.upi.edu
}

Received: 18-02-2020

Revised: 06-05-2020

Accepted: 12-06-2020

\section{The Order OfJava's Sufism: A Study Of Bagus Burham's Thinking On The Islamic Culture Of Java (1823-1870)}

\begin{abstract}
This research is explained about Raden Ngabehi Ranggawarchitecture in the history of Javanese literature and good Burbam (another name of rangawarchitecture related to the development of Theosufism teaching in Java). This research uses several problems, namely 1) how the history of Rangawarchitecture as a Javanese literary? 2) How is Javanese literary condition in the 19th century? 3) How ranggawarchitecture thought against Islam. This study used an historical approach by looking at a barrage of historical events and using a literature study approach.
\end{abstract}

Keywords: Kejawen, Ranggawarsita, Islam, Sufi, Java

\begin{abstract}
Abstrak
Penelitian ini menjelaskan tentang pemikiran Raden Ngabehi Ranggawarsita dalam sejarah perkembangan kesusasteraan Jawa sekaligus pemikiran Bagus Burham (nama lain dari Rangawarsita terkait dengan berkembangnya ajaran theosufisme di Jawa. Penelitian ini menggunakan beberapa rumusan masalah yakni 1) bagaimana riwayat Rangawarsita sebagai sastrawan Jawa? 2) bagaimana kondisi kesusasteraan Jawa di Abad ke-19? 3) bagaimana pemikiran Ranggawarsita terhadap Islam. Kajian ini menggunakan pendekatan historis dengan melihat rentetan peristiwa sejarah dan menggunakan pendekatan studi literatur.
\end{abstract}

Kata Kunci: Kejawen, Ranggawarsita, Islam, Sufi, Jawa

\section{PENDAHULUAN}

Dalam tradisi kepustakaan Jawa, Bagus Burham dianggap oleh Masyarakat Jawa sebagai pujangga terakhir ${ }^{1}$. Seorang Pujangga yang memiliki kemampuan untuk menggambarkan prediksi sekaligus pemahaman keislaman dapat dikupas secar tuntas melalui beberapa karyanya ${ }^{2}$. Khazanah sastra tulis Nusantara di Indonesia sangat kaya dan meliputi

${ }^{1}$ Zumrotul Mukaffa, "The Era of Uncertainty and Ethical Arrangement in Javanese Classical Texts: Disseminating Ranggawarsita's Works as Source of Islamic Ethics in Islamic Higher Education," Al-jami'ah: Journal of Islamic Studies 56, no. 2 (18 Desember 2018): 461-93, https://doi.org/10.14421/ajis.2018.562.461-493.

2 Anggita Dwi Astuti dan Andy Suryadi, "Pemanfaatan Museum Ranggawarsita sebagai Sumber Belajar Sejarah Bagi Siswa SMA Negeri Di Kota Semarang," Jurnal Profesi Keguruan 6, no. 1 (2020): 9-21. 
karya-karya dalam berbagai bahasa. Salah satu dari sekian khazanah sastra Nusantara tersebut ditulis dalam bahasa Jawa ${ }^{3}$. Pada abad ke-4 hingga ke-14 M, sastra Jawa Kuno berkembang pesat karena adanya beberapa kerajaan besar, seperti Kediri, Singasari, dan Majapahit yang berperan sebagai penyebar peradaban dan kebudayaan Hindu-Budha ${ }^{4}$.

Setelah keruntuhan kerajaan Majapahit pada tahun 1478 M, unsur-unsur budaya Islam mulai masuk dan berkembang di Jawa ${ }^{5}$. Pada masa Kerajaan Mataram Islam yang dipimpin Sultan Agung, banyak muncul buku-buku yang terpengaruh oleh ajaran tasawuf. Pada periode 1757-1881 M merupakan masa kebangkitan sastra. Salah satunya adalah naskah cibolek karya Yadisapura I. Pada periode inilah muncul tokoh Ronggowarsito yang oleh orang-orang Jawa dianggap sebagai bapak kebatinan atau kejawen ${ }^{6}$.

Seseorang dapat dikatakan sebagai seorang pujangga apabila memiliki kecerdesan dan daya ingat serta mampu memahami tanda-tanda perubahan sosial yang sebelumnya belum diketahui oleh orang banyak. Ranggawarsita juga merupakan sebagai seorang kritikus sosial dengan menjadikannya bahan kritikan menjadi sebuah kary sastra dengan memperhalus gaya bahasa yang digunakan pada karya sastranya ${ }^{7}$.

Perkembangan Kesusasteraan Jawa tentunya tidak terlepas dari peran para pujangga yang berkembang pada permulaan Abad ke-18 Masehi ${ }^{8}$. Kebanyakan karya-karya yang dihasilkan oleh para pujangga bertemakan tentang sosial yang menggambarkan dinamika masyarakat Jawa saat itu' ${ }^{9}$ Tidak sedikit menghasilkan karya-karya yang bertemakan Islam, mengingat saat itu Islam menjadi suatu ciri identitas sosial bagi Masyarakat Jawa ${ }^{10}$. Bagus Burham merupakan satu diantara banyak pujangga yang lahir dari kalangan keraton Kartasura. Bagus Burham seorang pujangga sekaligus penyair serta banyak karyanya yang bertemakan

3 Afrizal Prasadana dan Purwanto Purwanto, "Representasi Nilai Kearifan Ranggawarsita pada Kepemimpinan Kepala Dinas Penerangan Komando Armada II dalam Mewujudkan World Class Navy," representamen 6, no. 01 (2020).

4 Aris Aryanto dkk., "Social Criticism in the Text Scripture of Dharmasonya," Komunitas: International Journal of Indonesian Society and Culture 9, no. 1 (2017): 70-80.

5 Achmad Syafrizal, "Sejarah Islam Nusantara," Islamuna: Jurnal Studi Islam 2, no. 2 (5 Desember 2015): 235-53, https://doi.org/10.19105/islamuna.v2i2.664; Nor Huda, Islam Nusantara: sejarah sosial intelektual Islam di Indonesia (Ar-Ruzz Media, 2007).

${ }^{6}$ Saidun Derani, "Ulama Betawi dalam Perspektif Sejarah,” Al-Turas XIX (2013): 217-40.

7 Muhammad Luthfi Ubaidilah, "Konsep Ibn Al-'Arabĭ Dan Ranggawarsita Tentang Manusia (Sebuah Perbandingan Antara Sufisme Dan Kebatinan)," Misykah: Jurnal LPPM LAI BBC 1, no. 1 (18 Oktober 2017): 145-59, http://journal.bungabangsacirebon.ac.id/index.php/misykah/article/view/12.

8 Soebardi, "Raden Ngabehi Jasadipura I, Court Poet of Surakarta: His Life and Works," Indonesia, no. 8 (1969): 81-102, https://doi.org/10.2307/3350670.

9 Fahruddin Faiz, "Sufisme-Persia Dan Pengaruhnya Terhadap Ekspresi Budaya Islam Nusantara," ESENSLA: Jurnal Ilmu-Ilmu Ushuluddin 17, no. 1 (2016): 1-15.

${ }^{10}$ Ahmad Kholil, "ISLAM JAWA: Sufisme dalam Tradisi dan Etika Jawa," El Harakah 9, no. 2 (2007): 87. 
sosial dan agama. Mengenai pandangan konsep Islam yang dikemukakan oleh Ranggawarsita dituangkan dalam beberapa karya sastra salah satunya Serat Wirid Hidayatjati \& Serat Kalatidha yang membahas tentang konsep "Islamisme Jawa" menurut versinya. Dari hasil pemikirannya kemudian berkembangnya suatu istilah bagi Masyarakat Jawa yakni "Islam Kejawen". Islam Kejawen merupakan suatu konsep yang pertama kali diperkenalkan oleh Ranggawarsita dengan mempersatukan konsep Ke-Islam dan Kejawaan. Hal tersebut mengingat, kemunculan para pujangga juga seiring dengan munculnya kelompok "kebatinan" Jawa. Ranggawarsita melalui karya berusaha untuk mengakomodirkan kelompok kebatinan yang dianggap sebagai kelompok sesat dan memberikan kesempatan bagi kelompok tersebut untuk memahami dan mengamalkan ajaran Islam menurut versinya. Sehingga ketokohan Ranggawarsita sangat dihormati bagi masyarakat khususnya kelompok kebatinan ${ }^{11}$.

Karya-karya dari Bagus Burham merupakan awal pertumbuhan kebangkitan kembali perkembangan kesusasteraan Jawa pada Abad ke-19 Masehi. juga bisa dijadikan sebagai bahan pengajaran dengan kata lain sebagai materi dalam pendidikan sastra mulai dari sekolah hingga perguran tinggi juga dijadikan sebagai bahan kajian mengenai sejarah perkembangan kesusasteraan Jawa.

Penelitian ini menggunakan beberapa konsep diantaranya, 1) konsep multikultural, 2) etnografi, dan 3) alkulturasi. Pertama, Struktur masyarakat Indonesia ditandai oleh ciri veritikal dan horizontal. Secara horizontal ditandai dengan adanya kesatuan-kesatuan sosialberdsarkan perbedaan-perbedaan suku bangsa, perbedaan agama, adat istiadat, dan kedaerahan. Secara vertikal, struktur masyarakat ditandai adanya lapisan kasta dalam sosial masyarakat. Perbedaan tersebut tentunya bersifat majemuk yang merupakan suatu istilah untuk menggambarkan kondisi masyarakat Indonesia pada Masa Kependudukan Kolonial. Konsep masyarakat majemuk suatu tipe masyarakat daerah tropis di mana mereka yang berkuasa dan mereka yang dikauasi memiliki perbedaan ras.

Kedua, Istilah etnografi sebenarnya merupakan istilah antropologi. Etnografi merupakan embrio dari antopologi, yaitu lahir pada tahap pertama dari perkembangannya, yaitu sebelum tahun 800-an Masehi. Etnografi merupakan hasil-hasil catatan penjelajah Eropa ketika mencari rempah-rempah ke Indonesia. Mereka mencatat semua fenomena menarik

11 “11842-ID-unsur-unsur-ajaran-pemimpin-negara-dan-abdi-negara-di-dalam-teks-teks-pustakaraj.pdf,” t.t. 
yang dijumpai selama perjalanannya, antara lain berisi tentang adat-istiadat, susunan masyarakat, bahasa dan ciri-ciri fisik dari suku-suku bangsa tersebut ${ }^{12}$.

Etnografi juga menurut Le Compte, dkk. (t.t) merupakan prosedur penelitian kualitatif untuk menggambarkan, menganalisa, dan menafsirkan unsur-unsur dari sebuah kelompok budaya seperti pola perilaku, kepercayaan, dan bahasa yang berkembang dari waktu ke waktu. Fokus dari penelitian ini adalah budaya ${ }^{13}$. Budaya sendiri merupakan segala sesuatu yang berkaitan dengan perilaku manusia dan keyakinan. Termasuk di dalamnya adalah bahasa, ritual, ekonomi, dan struktur politik, tahapan kehidupan, interaksi, dan gaya komunikasi ${ }^{14}$.

Jadi bisa disimpulkan penelitian etnografi adalah penelitian kualitatif yang meneliti kehidupan suatu kelompok/masyarakat secara ilmiah yang bertujuan untuk mempelajari, mendeskripsikan, menganalisia, dan menafsirkan pola budaya suatu kelompok tersebut dalam hal perilaku, kepercayaan, bahasa, dan pandangan yang dianut bersama. Akulturasi adalah proses berpadunya kebudayaan lokal dengan kebudayaan yang berasal dari luar, lalu menghasilkan kebudayaan baru. Akulturasi dapat menimbulkan dua efek, yang pertama yaitu efek yang dapat dikatakan menguntungkan dan bernilai positif, dapat dikatakan seperti itu karena dari proses akulturasi tersebut dapat menghasilkan kebudayaan baru yang tinggi nilainya, dan memiliki manfaat ${ }^{15}$.

Namun disisi lain, alkulturasi juga terjadi pada masyarakat perkotaan sebagaimana yang dikutip oleh Foster (1965. hlm. 45) yang digambarkan bahwa alkulturasi pada masyarakat kota dengan menghilangkan budaya tradisional, munculnya pola individualisme, dan menumbuhkan perilaku hedonisme ${ }^{16}$. Tidak semua demikian yang mengatakan bahwa orang daerah ketika melakukan migrasi ke daerah kota seperti yang dikutip diatas dikarenakan masih beberapa orang yang justru tetap menguatkan nilai budaya daerahnya walaupun sedang merantau ke perkotaan ${ }^{17}$.

\footnotetext{
12 Todd Philip Elefson, Transactions for blessing (baraka): An ethnography of socio-religio-political power among men in the Santri Islam region of Java (Fuller Theological Seminary, School of Intercultural Studies, 2008), http://search.proquest.com/openview/7103763fb6818f60742618fd402039bd/1?pqorigsite $=$ gscholar\&cbl $=18750 \&$ diss $=\mathrm{y}$.

${ }^{13} \mathrm{John}$ W. Creswell, Educational research: planning, conducting, and evaluating quantitative and qualitative research, 4th ed (Boston: Pearson, 2012), 112.

${ }^{14}$ Koentjaraningrat, Javanese Culture, 2. impr (Singapore: Oxford Univ. Pr, 1990).

${ }^{15}$ Linda Lundgaard Andersen, "New Forms of Representations in Ethnografi: Authencity, Meaning and Critical Perspectives," 2008.

${ }^{16}$ Eko Handoyo, Studi masyarakat Indonesia (Semarang: Fakultas Ilmu Sosial, Universitas Negeri Semarang, 2007), 45 .

${ }^{17}$ Davis W. Houck dan David E. Dixon, Women and the Civil Rights Movement, 1954-1965 (Univ. Press of Mississippi, 2009).
} 


\section{METODE}

Data yang diolah berdasarkan dengan studi kepustakaan yakni dengan menggunakan berbagai macam sumber literasi yang mendukung dalam kajian ini ${ }^{18}$. Sumber-sumber yang digunakan menggunakan buku, jurnal, dan beberapa sumber internet yang dapat dipertanggung jawaban. Menggunakan pendeketan kualitattif artinya kajian ini ditulis berdasarkan penggambaran deskriptif dari sumber yang didapatkan. Juga menggunakan metodologi historis sebagai pengembangan kajian ${ }^{19}$.

Metode yang digunakan oleh penulis adalah metode studi konten isi yakni dengan menggunakan pendekatan studi literatur dari beberapa sumber dengan mengkaji beberapa temuan berupa pengumpulan buku-buku sebagai sumber referensi sekaligus pembanding sumber pada pembahasan ini. juga menggunakan metode historis untuk melihat perkembangan pembelajaran sejarah di Indonesia dengan melihat peristiwa berejarah di Indonesia. Menurut Helius Sjamsuddin mengatakan bahwa metode historis diawali dengan tahapan pengumpulan data, kritik atau verifikasi, interpretasi, dan penulisan seajarah sebagai kerangka berpikir dalam suatu penelitian yang sifatnya historis ${ }^{20}$.

Teori analisis isi seperti yang dikemukakan oleh Klaus Kripendoff ${ }^{21}$, analisis isi bukan sekadar menjadikan isi pesan sebagai objeknya, melainkan juga terkait dengan konsepsikonsepsi yang lebih baru tentang gejala-gejala simbolik dalam dunia komunikasi. Analisis isi adalah teknik penelitian untuk membuat inferensi-inferensi atau keteranganketerangan yang dapat ditiru (replicable) dan sahih datanya dengan memperhatikan konteksnya.

\section{PEMBAHASAN}

\section{Kondisi Keagamaan Masyarakat Jawa}

Islam menjadi salah satu pusat keagamaan sekaligus menjadi pusat kebudayaan dengan mengalkuturasikan agama dengan kebudayaan. Sejak awal proses Islamisasi para wali mengajarkan unsur magis-religius dengan menggunakan beberapa media perantara sebagai sarana menuju Islamisasi. Sunan Kalijaga mengajarkan Agama Islam dengan menyesuaikan kebutuhan dan kondisi masyarakat setempat. Identitas keagamaan juga menjadi simbol dalam perebutan tahta kekuasaan raja-raja yang telah diwariskan sejak Masa Hindu-Budha. Dengan mengacu gelar yang disematkan oleh para raja Mataram Islam dengan gelar

\footnotetext{
${ }^{18}$ Mestika Zed, Metode penelitian kepustakaan, Ed. 2 (Jakarta: Yayasan Obor Indonesia, 2008), 4.

19 Barbara M. Wildemuth, Applications of social research methods to questions in information and library science (Westport, Conn: Libraries Unlimited, 2009), 6.

${ }^{20}$ Helius Sjamsuddin, Metodologi Sejarah (Ombak, 2007), 30.

${ }^{21}$ Klaus Krippendorff, Analisis isi: pengantar teori dan metodologi (Rajawali Pers, 1980), 155.
} 
Senapati-ing-Alaga Sayidin Panatagama Khalitafullah Ingkang Tanah Jawi yang mentasbihkan dirinya mentasbihkan dirinya sebagai pemimpin dunia bagi Masyarakat Jawa ${ }^{22}$.

Aliran Kejawen berawal dari sebuah konsep munculnya Tassawuf dalam Islam. Terutama berkenaan dengan Hakikat Makrifatullah yang merupakan sebuah pola hubungan manusia sebagai ciptaan Tuhan berinteraksi dengan Tuhan sebagai pencipta melalui berbagai ritual dan syariat ke-Islaman. Konsep tersebut mengakar pada sebuah falsafah Orang Jawa yakni ungkapan agama ageming aji dan bisa ngaji, nanging aja dadi modin yang artinya agama merupakan suatu pedoman akan tetapi tidak menjdikannya suatu kaum yang fanatic terhadap ajarannya. ${ }^{23}$

Menurut Aboebakar Atjeh ${ }^{24}$ mengatakan, bahwa suatu esensi dari perkembangan ilmu tasawuf yakni membawa tingkatan secara spiritual dalam membangun hubungan konektifitas antara manusia dengan Tuhan-Nya. Ilmu Tasawuf merupakan suatu ilmu yang membatasi perihal nafsu keduniawian yang selama ini menjadi karakter pada manusia. Tasawuf berusaha agar segala sesuatu dapat dilakukan dengan ikhtiar ${ }^{25}$.

Berkembangnya agama Kejawen juga melahirkan ajaran yang berbentuk suluk dan primbon. Seyogyanya, ajaran lahir dari kalangan masyarakat agraris pedesaan Jawa dikarenakan daalam proses historisnya, Masyarakat Jawa sangat merindukan kekuatan dari euracakra (merupakan suatu pemahaman tentang munculnya Ratu Adil). Maka, didukungnya ajaran tersebut dan melahirkan suatu gerakan sosial baru yang dikenal sebagai Pamoring Kawula Gusti. Kebanyakan dari mereka menerima ajaran Islam hanya sebagai untuk pelengkap hidup manusia sebagai landasan utama dalam mempelajari dan mengamalkan ajaran Tassawuf. Ajaran Kejawen memiliki cara tersendiri untuk mendekatkan diri dengan Tuhannya yang tentunya seiiring dengan kemunculan berbagai paguron atau perguruan-perguruan berkenaan dengan masalah fisik, kebatinan, dan kejiwaan.

\footnotetext{
${ }^{22}$ Henk Schulte Nordholt, Bambang Purwanto, dan Ratna Saptari, Perspektif baru penulisan sejarah Indonesia (Yayasan Obor Indonesia, 2008), 56.

${ }^{23}$ Mulyanto,dkk.Biografi Pujangga Ronggowarsito. Jakarta: Departemen Pendidikan dan Kebudayaan. 1990. hlm. 27

${ }^{24}$ Atjeh Abubakar, Imu Tarekat (Jakarta: FA. H.M. Tawi dan Son Bag, 1966), 15; Atjeh Abubakar, Tarekat Dalam Tasawuf(Kelantan: Pustakan Aman Press SDN, 1933), 5.

${ }^{25}$ Ahmad Ahmad, "Epistemologi Ilmu-Ilmu Tasawuf," Jurnal Ilmiah Ilmu Ushuluddin 14, no. 1 (2016): 5966; Abuddin Nata, Akblak tasawuf (Jakarta: Rajawali Pers, 2010); Muhammad Afif Anshori, "Kontestasi Tasawuf Sunnî Dan Tasawuf Falsafî Di Nusantara," Teosofi: Jurnal Tasawuf Dan Pemikiran Islam 4, no. 2 (17 September 2015): 309-27, https://doi.org/10.15642/teosofi.2014.4.2.309-327.
} 
Menurut Endaswara ${ }^{26}$, mengatakan bahwa kekuatan dari mistik Kejawen yakni penyatuan kembali ruh manusia dengan Tuhan, dan peremajaan hidup kembali. Seyogyanya, dalam pandangan masyarakat Jawa antara Tuhan dengan manusia saling melengkapi. Konsep Dzat digambarkan sebagaikan kekuatan penuh dan tersentral. Pelukisan masyarakat Jawa terhadap Tuhan selalu dikaitkan dengan upaca kesakralan untuk melakukan interaksi dengan Tuhan-Nya ${ }^{27}$.

\section{Kondisi Kesusasteraan Jawa}

Permulaan Abad ke-19 proses perkembangan sastra di Jawa didominasi oleh pengaruh kekuasaan Banyak sastra epos yang menceritakan bentuk pengabdian para raja dan menceritakan tentang kehidupan kstarian kerajaan. Maka sifat dari kesusasteraan tersebut bersifat istanasentris. Mengenai posisi struktural yang diberikan oleh raja, para pujangga endapatkan posisi sebagai sekretaris kerajaan yang ditugaskan untuk menyelamatkan dan membuat kitab-kitab baru. Cerita yang dibangun bertujuan memiliki kesetiaan terhadap kerajaan.

Terdapat nilai dan unsur karya sastra tersebut mengandung estetika pada penggunaan diksi dan gaya bahasa. Seluruh tema yang dibawakan menceritakan tentang pujian terhadap raja atas kekuasannya yang ditandai dengan sifat kefeodalannya. Sifat tersebut berbentuk dalam bentuk nasehat, wejangan, wulang-waruk, ramalan, kidungan, dan sebagainya. Disisi lain tidak setidikit dari kesusasteraan bertemakan tentang kepribadian yang luhur dan bertanggung jawab kepada Tuhan atau 'Sang Hayang Manon" dalam falsafah Masyarakat Jawa ${ }^{28}$.

Karya sastra yang bertemakan sosio-religius mencertakan tentang segala suatu peristiwa yang terjadi sudah ditakdirkan oleh Tuhan Yang Maha Esa. Posisi Tuhan sebagai dalang yang arrtinya mentakdirkan sesuatu, sedangkan manusia sebagai wayang sebagai pihak yang enjalankan atas kuas yang diberikan oleh Tuhan tersebut.

Karya sastra saat itu mengalami sebuah proses modernisasi pada gaya dan corak kebahasaan. Pengaruh unsur Belanda melalui kebijakan politik yang tidak bisa dipisahkan dari segi ketatabahasaan. Sebagai contoh perubahan aksara yang semula meenggunakan huruf Jawa kemudian dialihkan mengguunakan hururf Latin dalam penulisannya. Tujuannya demi kepentingan pengarsipan bagi Kolonial Belanda.

\footnotetext{
${ }^{26}$ Suwardi Endraswara, Agama Jawa: ajaran, amalan, dan asal-usul kejawen (Narasi, 2018), 31.

${ }^{27}$ Clifford Geertz dan Taufik Abdullah, Agama Jawa: abangan, santri, priyayi dalam kebudayaan Jawa (Depok, Indonesia: Komunitas Bambu, 2013), 14.

${ }^{28}$ Anjar Any, Raden Ngabehi Ronggowarsito, apa yang terjadi? (Semarang: Aneka, 1980), 35.
} 


\section{Biografi Ranggawarsita}

Raden Ngabehi Ronggowarsito yang memiliki nama asli Bagus Burhan, adalah putra dari Raden Mas Pajangswara. Bagus Burhan adalah cucu dari Yosodipuro II, pujangga utama Kasunanan Surakarta. Dari silsilahnya, Bagus Burhan memiliki darah seorang bangsawan dalam dirinya. Dari ayahnya, ia memiliki darah keturunan Sultan Pajang, Sultan Hadiwijaya, sedangkan dari ibunya ia memiliki jalur keturunan dari Raden Patah, Sultan Demak Bintoro. $^{29}$

Sekembalinya di Surakarta, Bagus Burhan mendapat didikan lagi dari kakeknya sendiri, yaitu Raden Tumenggung Sastronegoro. Ia juga diambil sebagai cucu angkat oleh Panembahan Buminoto (adik Pakubuwana IV). Dalam perjalanan karirnya, ia diangkat sebagai Carik Kadipaten Anom bergelar Mas Pajanganom pada tanggal 28 Oktober 1819. Pada masa pemerintahan Pakubuwana V (1820-1823), karier Burhan sempat tersendat, karena konon Pakubuwana V kurang begitu suka dengan Panembahan Buminoto yang selalu mendesak agar pangkat Bagus Burhan dinaikkan.

Pada masa Kerajaan Kartasura, banyak muncul tradisi kepustakaan Mistik Kejawen yang merupakan adaptasi atau saduran dari karya Kesusasteraan Melayu Persia. Tradisi ini memasuki puncak perkembangan pada masa kerajaan Surakarta dengan berkembangnya kesusasteraan yang bermutu. Falsafah yang dituliskan oleh para pujangga pada masa tersebut berusaha untuk membangkitkan semangat orang-orang kepada masa keemasan Sastra di era Masa Hindu-Budha. Kakek dari Bagus Burham, Yosodipuro I dan Yosodipuro II menjadi pelopor dalam penyempurnaan kesusasteran terutama terletak dari penggunaan gaya bahasa.

Pada tanggal 9 November 1821 Bagus Burhan menikah dengan Raden Ayu Gombak, putri dari Adipati Cakraningrat. Ia dan istrinya juga sempat ikut mertuanya ke Kediri, sebelum akhirnya Bagus Burhan memutuskan untuk berkelana dengan ditemani Ki Tanujoyo. Bagus Burhan berkelana sampai ke Pulau Bali untuk berguru kepada Kyai Tunggulwulung di Ngadiluwih, Kyai Ajar Wirakanta di Ragajambi dan Kyai Ajar Sidalaku di Tabanan, Bali. Dalam kesempatan berharga itu, ia berhasil membawa pulang beberapa catatan peringatan perjalanan dan kumpulan kropak-kropak serta peninggalan lama dari Bali dan Kediri ke Surakarta ${ }^{30}$. hlm. 40

${ }^{29}$ Mulyanto,dkk. Biografi Pujangga Ronggowarsito. Jakarta: Departemen Pendidikan dan Kebudayaan. 1990.

${ }^{30}$ Purwadi, Mistike kejawen pujangga Ronggowarsito (Media Abadi, 2005), 34. 
Riwayat keseniman Bagus Burham masih bisa dilacak lebih jauh lagi. Dari pihak ibu ia masih keturunan Sujonopuro atau yang lebih dikenal sebagai Pangeran Karanggayam, pujangga kerajaan Pajang. Ia adalah seorang sastrawan besar buku yang terkenal sampai kini, yaitu Serat Niti Suri sebuah buku yang beris ajaran tentang etika kehidupan.Sehingga sama sekali bukan hal yang aneh jika Bagus Burham tertarik menekuni dunia sastra. Apalagi pada saat itu, yaitu menjelang awal abad XIX adalah masa puncak salah satu genre dalam sejarah kesusastraan Jawa yang dikenal dengan tradisi Islam Kejawen.

Bagus Burhan diangkat sebagai Panewu Carik Kadipaten Anom bergelar Raden Ngabei Ronggowarsito, menggantikan ayahnya yang meninggal di penjara Belanda tahun 1830. Lalu setelah kematian Yasadipura II, Ranggawarsita diangkat sebagai pujangga Kasunanan Surakarta oleh Pakubuwana VII pada tanggal 14 September 1845.

Ranggawarsita memiliki murid-murid orang asing, terdiri dari pegawai bahasa di Surakarta seperti CF Winter, JFC Grricke, dan Dr Falmer Van Den Broug. Mereka belajar bahasa dan kesusastraan Jawa kepada Ranggawarsita. Sebaliknya Ranggawarsita juga banyak belajar kesusastraan barat dari mereka. Selama hidupnya, Ranggawarsita telah banyak menghasilkan karya-karya yang tidak hanya bersifat kesusastraan, tapi juga mengandung unsur hukum, ekonomi, filsafat, sejarah, kebatinan, kemasyarakatan, ramalan, dan lain sebagainya. Karyanya antara lain Serat Paramayoga, Serat Pustakaraja Purwa, Serat Sabda Jati, Serat Sabdatama, Serat Jaka Lodhang, Serat Wedharaga, atau Serat Kalatida. ${ }^{31}$

\section{Karya-karya Ranggawarsita Dalam Kesusasteraan Jawa}

Pada tanggal 14 September 1845 Bagus Burham dianggat menjadi pujangga Kesunanan Surakarta dan diberikan gelar "Ngabehi”. Naskah-naskah babad cenderung bersifat simbolis dalam menggambarkan keistimewaan tentang dirinya. Misalnya, ia dikisahkan mengerti bahasa binatang. Ini merupakan simbol bahwa, Bagus Burham sangat peka terhadap keluh kesah rakyat kecil. Pasca pengangkatannya, Bagus Burham kemudian menuliskan sebuah karangan yang berjudul Serat Jayeng Baya. Buku tersebut merupakan kumpulan-kumpulan puisi Bagus Burham yang terdidir 250 bait puisi, menceritakan tentang seseorang dalam menjalani proses pencarian jati diri.

Demi kepentingan penguasa saat itu Bagus Burham menuliskan dua buah serat yang berjudul Paramayoga dan Pustaka Raja Purwa. Kedua karya sastra tersebut saling keterkaitan dan menceritakan tentang Sejarah Nabi Adam dengan kaitan Mitologi Orang-Orang Jawa

\footnotetext{
${ }^{31}$ Fakultas Ushuluddin, "Konsep keadilan dalam serat kalatidha karya raden ngabehi ranggawarsita," 2014.
} 
hingga pada akhirnya menceritakan silsilah raja-raja. Raja memanfaatkan tugas para pujangga untuk menyusun mitos-mitos tentang leluhur mereka. Serat ini mengandung unsur filsafat sejarah terutama mengenai asal usul Orang Jawa.

Bagus Burham juga menulis tentang karya Serat Cemporet yang menceritakan tentang tiga orang putra raja yang lari dari istana dan berguru di sebuah padeopakan milik Buyut Cemporet. Dalam tulisan ini banyak diceritakan tentang kesaktian dan kehabatan para tokoh yang tertuang dalam serat tersebut.

Memasuki paruh kedua abad 19 aktivitas kesusasteraan Bagus Burham semakin luas. Bagus Burham kemudian melakukan kerjasama dengan redaktur dan majalah milik Kolonial Belanda. Hal tersebut ketika Jonas Portier (sebuah majalah harian Kolonial) menerbitkan sebuah majalah yang berbahasa Jawa, Bramartani selain itu Bagus Burham bekerjasama dengan Van der Vlis dan C.F. Winter dalam menuliskan sebuah buku yang berujudul Kawi-Javaansch Woordenboek. Bentuk kerjasama tersebut kemudian dituangkan dalam sebuah dokumen kesepakatan perjanjian. ${ }^{32}$

Karir sebagai pujangga tidak berjalan mulus, Bagus Burham kemudian menuliskan karya-karya yang sifatnya profetis. Ini dilakukan oleh Bagus Burham ketika hubungan dengan Pakubuwono VI kurang begitu baik. Selama masa kepemimpinannya, Bagus Burham selalu mengkrittisi suasana dalam kraton juga mengkritisi kondisi sosial masyarakat sekitar. Bagus Burham menuliskan sebuah Serat Kalatidha menceritakan tentang kekacauan sekaligus masa-masa sulit yang dialami oleh Kasunanan Surakarta. Menurut Musman, kata kalatidha berasal dari dua kata yaitu kala dan tidha. Kala artinya zaman atau masa, sedangkan tidha artinya bimbang atau samar atau cacat. Dapat disimpulkan bahwa Kalatidha secara harfiah merupakn jaman penuh keraguan ${ }^{33}$.

Kemudian dari karya sastra tersebut maka Bagus Burham mengenalnya sebagai Zaman Edan atau Zaman Kekacuan yang berati menggambarkan bahwa saat itu terjadi pola perubahan sosial Masayarakat Jawa dan tindakan sewenang-wenang yang dilakukan oleh raja, serta pengaru Budaya Kolonial telah mengakar dan masuk di lingkungan keraton. Penggambaran Bagus Burham pada masa itu menggambarkan kondisi sosial di lingkungan sekitar keraton Surakarta. Banyak para penguasa tidak memberikan teladan, banyak yang

\footnotetext{
32 Norman, A.Zaman Edan Ronggowarsito. Yogyakarta: Forum. 2013. hlm. 163

33 R. Ng Ronggowarsito, Zaman edan (Narasi, 2017), 163; Purwadi, Ramalan zaman edan Ronggowarsito (Media Abadi, 2004).
} 
meninggalkan norma, dan cendekiawan yang selalu meragukan unsur lokalitas Jawa. Sehingga Bagus Burham melakukan kritikan sosial melaui karya sastra tersebut.

\section{Pandangan Bagus Burham Mengenai Islam}

Bagus Burham menuliskan suatu karya sastra yang berjudul Serat Wirid Hidayat Jati. Karya tersebut berisikan tentang pemahaman Bagus Burham mengenai Fiqih Islam menurut Kebudayaan Jawa. Menurut Hariwijaya ${ }^{34}$ Ranggawarsita telah membagi tujuh bagian mengenai hakikat manusia yaitu:

a. Hayyu artinya hidup, disebut sebagai atma (dalam istilah Jawa), terletak diluar dzat

b. Nur artinya cahaya, disebut pranawa (dalam istilah Jawa)

c. Sir artinya rasa, disebut pramana (dalam istilah Jawa)

d. Roh artinya jiwa, disebut suksma (dalam istilah Jawa)

e. Nafsu artinya angkara (dalam istilah Jawa)

f. Akal artinya budi (dalam istilah Jawa)

g. Jasad artinya badan (dalam istilah Jawa)

Uraian terseut enggambarkan bahwa dzat Tuhan seperti yang digambarkan sebagai satu titik pusat yang dilangkari oleh tujuh bagian. Kesemuanya tidak dapat dipisahkan dan merupakan perwujudan asli dari sifat manusia sebagai mahluk ciptaan Tuhan. Penamaan Wirid Hidayat Jati merupakan suatu esensi yang berisikan pesan moral kepada seluruh manusia agar selalu berada di dalam perintah Tuhan dengan menjalankan syariat atau ketentuan yang Tuhan berikan.

Konsep keislaman yang dibangun oleh Bagus Burham juga tertuang pada Serat Wedhatama yang berisikan tentang konsep Makrifatullah dengan asumsinya bahwa tujuan hidup tertinggi dalam kehidupan sejatinya akan kembali kepada Tuhan sebagai penentu qodrat dan takdir hidup manusia. Menurut Simuh (1988. hlm. 252) Ilmu mistik yang dituangkan dalam Serat Wedhatana merupakan sembah raga, cipta, jiwa, dan rasa. Keempat macam sembah ini secara berurutan merupakan hasil pemodifakian ajaran tasawuf ${ }^{35}$.

Pada serat ini dikenalkannya konsep ajaran Kawula Gusti yang merupakan harmonitas sosial. Konsep Kawula Gusti merupakan konsep ketauhidan dengan mengibaratkan

\footnotetext{
${ }^{34}$ M. Hariwijaya, Islam kejawen: sejarah, anyaman mistik, dan simbolisme Jawa (Gelombang Pasang, 2004), 316.

35 Simuh, Mistik Islam kejawen Raden Ngabehi Ranggawarsita: suatu studi terhadap serat Wirid Hidayat Jati (Penerbit Universitas Indonesia, 1988), 252.
} 
Tuhan sebagai raja sedangkan mannusia sebagai Tuhan dengan menjalankan perintah atas rajanya, maka terciptalah keselarasan dan keseimbangan pada hidup manusia.

Baik Serat Wirid Hidayat Jati dan Serat Wedhatama keduanya memiliki pengaruh Islam yang begitu kuat dengan menjadikannya Al-Qur'an sebagai referensi dalam penulisan karya-karya yang ditulis oleh Bagus Burham. Terlihat jelas unsur sinkretisme budaya antara Hindu-Budha, Jawa, dengan Islam dalam corak pemahaman karya Bagus Burham.

Konsep gambaran penciptaan manusia dengan menggunakan dasar teori martabat tujub yang digunakan Bagus Burham merupakan buah pikiran Muhammad Ibn Fadlillah alBurhanpuri dalam al-Tubfah al-Mursalab ila Rub al-Nabiy. Pemikiran kejadian manusia dan penciptaan alam secara umum melalui proses tajalli atau emanasi Tuhan bersumber dari faham wujudiyah. Karena itu, pemikiran dasar dalam martabat tujuh adalah juga wujudiyah. Kesimpulan yang sama juga ditegaskan oleh Simuh bahwa dasar ajaran tajalli yang bersumber dari faham martabat tujuh adalah dari penganut faham wabdat al-wujud. Dengan demikian, ajaran martabat tujuh versi Ronggowarsito adalah juga faham wujudiyab ${ }^{36}$

Ajaran tasawuf menurut pemikiran Ronggowarsito tertuangkan ke dalam salah satu karyanya yaitu Serat Wirid Hidayat Jati. Di dalam Wirid Hidayat Jati mengajarkan paham kesatuan manusia dengan Tuhan. Paham ini mengajarkan bahwa manusia berasal dari Tuhan, oleh karena itu, harus berusaha untuk kembali dengan Tuhan. Adapun jalan untuk kembali kepada Tuhan yaitu manusia sempurna (insan kamil). Pengertian insan kamil menurut Al-Ghazali yaitu, manusia sempurna didapat karena menjalani laku tasawuf dan sebagai manusia yang setaraf dengan waliyullah yang dapat mencapai manunggal dengan Tuhan atau manunggaling Kawula Gusti ${ }^{37}$.

Konsep manunggaling Kawula Gusti dalam wirid hidayat jati, merupakan gubahan dari ajaran tajalli yang berasal dari paham martabat tujuh. Tajalli berarti memperlihatkan keluar. Dasar pemikiran ini merupakan suatu pemikiran ajaran tasawuf yang berpaham wahdatul wijud. Tajalli merupakan kondisi kerohanian yang mampu menyaksikan cahaya penjelmanNya dalam nama-Nya.

Konsep manusia sempurna (insan kamil) yang ada pada Serat Wirid Hidayat Jati, bukan merupakan konsep manusia sempurna sebagaimana para sufi sebelumnya, seperti Al-Ghazali, Ibnu 'Arabi, dan Syekh Hamzah Fansuri. Kata insan kamil yang ada pada serat

${ }^{36}$ A Pendahuluan, "( Sebuah Perbandingan Antara Sufisme Dan Kebatinan ) Muhammad Luthfi Ubaidillah ( Staf Ahli Bidang Penelitian dan Pengabdian Masyarakat Kemenag RI ) Abstrak Hakikat manusia menjadi suatu kajian yang selalu menarik untuk diperbincangkan di berbagai budaya ," t.t., 145-59.

${ }^{37}$ Alwi Shihab, Islam sufistik: "Islam pertama” dan pengarubnya bingga kini di Indonesia (Mizan, 2001), 56. 
Wirid Hidayat Jati merupakan proses penciptaan manusia secara utuh. Adapun manusia yang sempurna atau sudah mencapai kesempurnaan dalam Wirid Hidayat Jati, dibedakan menjadi dua golongan yaitu, golongan awam dan orang khawas. Seperti yang sudah dijelaskan sebelumnya bahwa ajaran manunggaling Kawual Gusti dalam pemikiran Ronggowarsito yang terserat dalam Wirid Hidayat Jati yaitu, manusia bisa menyatu atau bertemu dengan Tuhan ketika sudah mencapai ajal (kematian)

Bagus Burham menjelaskan konsep Manunggal Ing Kawula Gusti yang sebenamya masih sangat kontroversial dikarenakan dianggap dalam mempermainkan syahadat Islam yang bunyinya (Mahmudi. 2012. blm. 105):

"Aku bersaksi kepada Drat-Ku sendiri, bahwa sebenarnya tidak ada Tuban selain Aku, dan bersaksi bahwa sebenarnya Muhammad itu utusan-Ku. Sebenarnya Allah itu Badan-Ku, Rasul rahsa-Ku, dan Mubammad cabaya-Ku's8.

Konsep tersebut merupakan konsep "nyawiji” sebuah manifesto wujud dari iman itu sendiri. iman adalah satu atau ahad atau esa. Tuhan yang esa dan tidak akan ada Tuhan yang lainnya. Tuhan hanya suka dengan hal yang satu saja, tidak mau diduakan atau diselingkuhi. Wujud yang satu ini harus ditegakkan dalam aspek kehidupan sehari-hari. Tidak ada kata bercabang, bercabang adalah perlambang lidah ular, dan karena bercabang maka tujuannya jelas akan berbeda arah. Nyawiji juga disebut manunggal adalah dua unsur menjadi satu, maka konsep manunggaling kawula lan gusti bukan berarti lalu manusia menjadi satu dengan Tuhan. Manusia adalah manusia dan Tuhan adalah Tuhan. Manunggal disini adalah menyatunya antara gerak lahir dan batin dalam menyembah Tuhan. Ketika ikhrar sudah dikumandangkan, takbirotul ikhram, maka yang ada dalam mulut, hati,tangan, kaki, mata dan sebagainya hanyalah Tuhan.

Terakhir Bagus Burham menuliskan Serat Parmoling Kawula Gusti yang menceritakan tentang proses dzikir manusia sebagai bentuk peribadatan. Perenungan yang dilakukan merupakan perenungan kepada Tuhan dengan hati penuh rindu.Sesungguhnya yang ada di alam terpancar dari kehendak Tuhan. Seseorang yang telah dziir bagi Bagus Burham merupakan seseorang yang mengharapkan keridhaan atas kekuasaan Tuhan sebagai pencipta Umat Manusia (Karomi, K. 2013. hlm. 292) ${ }^{39}$.

\section{Unsur Sejarah Dalam Filsafat Bagus Burham}

Karya-karya yang dihasilkan dari Bagus Burham selain berunsurkan tentang keislam juga berunsurkan sejarah. Maksud sejarah disini adalah bersifat ramalan sejarah.

\footnotetext{
${ }^{38}$ Mahmudi, Wirid mistik Hidayat Jati: mutiara pemikiran teologi Islam kejawen (Pura Pustaka, 2005), 105.

39 Kholid Karomi, "Tuhan dalam Mistik Islam Kejawen (Kajian atas Pemikiran Raden Ngabehi Ranggawarsita)," Kalimah 11, no. 2 (2013): 287, https://doi.org/10.21111/klm.v11i2.97.
} 
Bagus Burham mampu meramalkan masa depan dengan melihat fenomena-fenomena yang gejalanya hampir sama dengan masa lalu ${ }^{40}$. Kemampuan ramalannya kemudian dituangkan dalam sebuah Serat Sabda Jati tepat delapan hari menjelang kematian Bagus Burham pada tanggal 24 Desember 1873. Beberapa menyebutkan bahwa kematian dari Bagus Burham diakibatkan oleh campur tangan Belanda mengingat saat itu hubungan antara Bagus Burham dengan pejabat kolonial dan Paku Buwono VI kurang begitu harmonis. Sehingga banyak menganggap terjadi persengkokolan diantara keduanya untuk membunuh Bagus Burham.

Dalam kehidupan sehari-hari, Ronggowarsito terpaksa menyesuaikan diri. Bergaul dan berkawan dengan tokoh-tokoh pemerintah dan sarjana Belanda. Namun cetusan batinnya, tidak menyukai tindak tanduk pemerintah colonial Belanda. Ronggowarsito menamai jaman yang sedang dialami itu sebagai jaman edan. Daalam serat sabda jati jaman yang serba sulit atau jaman edan, disebut jaman pakewnh atau kalabendu Hal ini diterangkan sebagai berikut :

Orang-orang dalam jaman pakewub (edan), kerendahan budinya makin menjadi. Jadi, kekacauan bertambah, banyak orang berhati sesat (buruk), melanggar peraturan yang benar, kesetiaan sudah tiada terlihat.

Bagi orang yang tahu akan kebenaran, dalam hati terasa ewuh (bingung), apabila tidak turut berbuat sesat, hidupnya akan menjadi merana, kalau ikut menjadi rendah budi pakertinya. Tindakan seperti itu, berarti tak percaya akan kemurahan dan kekuasaan Tuhan yang menciptakan segala-galanya. Apabila memohon dengan bersungguh hati pasti mendapat anugerah dari kemurahan Tuhan.

Tuhan mengabulkan semua permohonan, apabila di sertai kesungguhan, Allah pasti membeli pertolongan, tidak akan kekurangan makan serta pakaian. Segala yang diinginkan akan terlaksana ${ }^{41}$.

Kemampuan memprediksi yang dimiliki oleh Bagus Burham sejatinya menjadi kemampuan yang wajib kala itu dimiliki oleh setiap pujangga. Posisi pujangga tidak hanya sebatas menulis akan tetapi juga mampu menjawab berbagai persoalan spiritual, dan terkadang dijadikan sebagai penasehat sekaligus arah penentu kebijakan kerajaan. Kelebihan lain dari Bagus Burham yakni mampu menangkap fenomena-fenomena alam yang belum tentu dimiliki oleh setiap orang. Ramalan Ronggowarsito seringkali terhubung dengan ramalan Jayabaya. Ramalan Jayabaya terdiri dalam kitab asrar, jayabaya kidung,

\footnotetext{
40 “31336-73015-1-SM.pdf," t.t.

${ }^{41}$ Bagus Wahyu Setyawan, "Kajian Pragmatik Mengenai Tindak Tutur Direktif dalam Serat Joko Lodhang Karangan Raden Ngabehi Ranggawarsita,” Jalabahasa: Jurnal Ilmiah Kebahasaan 14, no. 2 (2018): 67-79.
} 
jayabaya prabitiwakya, kidung musarar, jayabaya pranitiradya, jangka ratu galuh kidung, jayabaya pancaniti, kidung lambing Negara dan masih banyak lagi.

Ramalan Jayabaya merangkum waktu 2100 rembulan, terbagi dalam jaman besar alias kali ialah swara, yoga, dan sangara. Tiap kali berlangsung 700 tahun dan dibagi atas tujuh jaman kecil alias kali, masing-masing 100 tahun. Seluruhnya berlangsung antara tahun rembulan 0-2100 alias tahun 78-2163 .

Termasuk jaman besar pertama kali swara ialah kala kukila, badha, brawa, tirta, rwabara, rwabawa dank ala purwa. Jaman besar kedua kali Yoga ialah kal brata, dwara, dwapara, praniti, tetaka, wisesa, dan kala wiyasa. Jaman besar terakhir kali sengsara terdiri atas jaman-jaman kecil kala jangga, sakti, jaya, bendhu alias jaman edan, suba, sumbaga dan kala surata.

\section{UCAPAN TERIMA KASIH}

Penulis mengucapkan terimakasih kepada Andi Suwirta, M.Hum. selaku mata kuliah Sejarah Islam Indonesia yang telah merekomendasikan sumber-sumber sebagai bahan rujukan dalam pembahasan ini. Penulis juga mengucapkan terimakasih kepada kawan-kawan yang telah membantu dalam penulisan ini sehingga menjadi suatu karya ilmiah dalam bentuk artikel.

\section{KESIMPULAN}

Bagus Burham atau Ronggowarsito memiliki peran dalam kontribusi baik dalam kesusasteraan Jawa melalui pemikiran-pemikirannya mengenai masalah keislaman. Bagus Burham dianggap sebagai pribadi yang memiliki nilai dan karakter luhur dalam melestarikan adat dan budaya Jawa. Belatarbelakang seorang santri mampu menuliskan berbagai kesusasteraan dalam mengenai tata cara peribadatan yang kemudian dimodifikasikan ke dalam tradisi spiritualisme Jawa. Ranggawarsita juga mencampurkan unsur klenik (sesuatu yang sifatnya magisisme) dalam paham kebatinannya. Hal itu terlihat dalam konsep insan kamilnya nya. Bahwa manusia yang telah mengalami kesatuan dengan Tuhan, akan menjadi sakti sehingga merupakan asal usul dari konsep nyawiji. Apa yang dikatakannya akan terjadi.

Oleh karena itu, perlu ketelitian, kejelian dan kewaspadaan dalam mengkaji ajaran ini, dengan mengedepankan sikap kritis. Maka kitab atau kesusasteraanya sering dijadikan sebagai bahan referensi utama dalam memahami aliran Islam Kejawen dan disisi lain juga perkembangan aliran kebatinan semakin subur pada era Abad ke-19 Masehi. Ronggowarsito dilahirkan dari keluarga seorang pujangga. Ia mendapatkan pendidikan dalam pesantren Ki Imam Besari. Imam Besari merupakan tokoh agama Islam yang terkemuka pada abad ke-19. 
Selain itu, ia juga ahli dalam bidang kebatinan. Maka tidak heran dari pesantren seperti ini menghasilkan seorang yang ahli dalam kebatinan dan taat beragama.

Pemikiran tasawuf Ronggowarsito terpengaruh paham tasawuf wabdatul wujud atau dalam bahasa Jawa dikenal dengan manunggaling Kawula Gusti. Paham wabdatul wujud ini merupakan suatu paham ajaran tasawuf falsafi yang dipopulerkan oleh sufi yang bemama Ibnu Arabi. Pemikiran Ronggowarsito tentang manunggaling kawula Gusti bersumber dari ajaran martabat tujuh yang merupakan ajaran tasawuf yang dikenalkan oleh tokoh sufi dari Aceh yaitu Hamzah Fansuri.

Ajaran tasawuf Islam, mempunyai pengaruh besar terhadap kehidupan masyarakat Jawa yang cenderung gemar mendalami ilmu kebatinan. Pada masa perkembangan kepustakaan Jawa. Kemunculan tokoh Ronggowarsito dianggap oleh masyarakat Jawa sebagai seorang tokoh kebatinan. Dari karya-karya sastranya banyak dijadikan suatu rujukan bagi kebatinan yang ada di Jawa. Ranggawarsita telah banyak mengajarkan tentang cara dan ramalan terkait dengan kondisi sosial Masyarakat Jawa saat itu. Ranggawarsita juga telah memberikan pengaruh positif terkait dengan pembaharu Islam di Tanah Jawa dengan menjadikan unsur budaya sebagai penakan utama dalam hal pemikiran dan gagasannya. Hubungan Ranggawarsita dengan Belanda juga kurang baik. Meskipun ia memiliki sahabat dan murid seorang Indo bernama C.F. Winter, Sr., tetap saja gerak-geriknya diawasi Belanda. Ranggawarsita dianggap sebagai jurnalis berbahaya yang tulisan-tulisannya dapat membangkitkan semangat juang kaum pribumi.

\section{REFERENSI}

“11842-ID-unsur-unsur-ajaran-pemimpin-negara-dan-abdi-negara-di-dalam-teks-tekspustakaraj.pdf," t.t. “31336-73015-1-SM.pdf,” t.t.

Abubakar, Atjeh. Ilmu Tarekat. Jakarta: FA. H.M. Tawi dan Son Bag, 1966.

—. Tarekat Dalam Tasawuf. Kelantan: Pustakan Aman Press SDN, 1933.

Ahmad, Ahmad. "Epistemologi Ilmu-Ilmu Tasawuf." Jurnal Ilmiah Ilmu Ushuluddin 14, no. 1 (2016): 59-66.

Andersen, Linda Lundgaard. "New Forms of Representations in Ethnografi: Authencity, Meaning and Critical Perspectives,” 2008. 
Anshori, Muhammad Afif. "Kontestasi Tasawuf Sunnî Dan Tasawuf Falsafî Di Nusantara." Teosofi: Jurnal Tasawnf Dan Pemikiran Islam 4, no. 2 (17 September 2015): 309-27. https://doi.org/10.15642/teosofi.2014.4.2.309-327.

Any, Anjar. Raden Ngabebi Ronggowarsito, apa yang terjadi? Semarang: Aneka, 1980.

Aryanto, Aris, Bani Sudardi, Andrik Purwasito, dan Abdullah Wakit. "Social Criticism in the Text Scripture of Dharmasonya." Komunitas: International Journal of Indonesian Society and Culture 9, no. 1 (2017): 70-80.

Astuti, Anggita Dwi, dan Andy Suryadi. "Pemanfaatan Museum Ranggawarsita sebagai Sumber Belajar Sejarah Bagi Siswa SMA Negeri Di Kota Semarang." Jurnal Profesi Keguruan 6, no. 1 (2020): 9-21.

Creswell, John W. Educational research: planning, conducting, and evaluating quantitative and qualitative research. 4th ed. Boston: Pearson, 2012.

Derani, Saidun. “Ulama Betawi dalam Perspektif Sejarah.” Al-Turas XIX (2013): 217-40.

Elefson, Todd Philip. Transactions for blessing (baraka): An ethnography of socio-religio-political power among men in the Santri Islam region of Java. Fuller Theological Seminary, School of Intercultural Studies, 2008. http://search.proquest.com/openview/7103763fb6818f60742618fd402039bd/1?pqorigsite $=$ gscholar\&cbl $=18750 \&$ diss $=\mathrm{y}$.

Endraswara, Suwardi. Agama Jawa: ajaran, amalan, dan asal-usul kejawen. Narasi, 2018.

Faiz, Fahruddin. "Sufisme-Persia Dan Pengaruhnya Terhadap Ekspresi Budaya Islam Nusantara.” ESENSLA: Jurnal Ilmu-Ilmu Ushuluddin 17, no. 1 (2016): 1-15.

Geertz, Clifford, dan Taufik Abdullah. Agama Jawa: abangan, santri, priyayi dalam kebudayaan Jawa. Depok, Indonesia: Komunitas Bambu, 2013.

Handoyo, Eko. Studi masyarakat Indonesia. Semarang: Fakultas Ilmu Sosial, Universitas Negeri Semarang, 2007.

Hariwijaya, M. Islam kejawen: sejarah, anyaman mistik, dan simbolisme Jawa. Gelombang Pasang, 2004.

Houck, Davis W., dan David E. Dixon. Women and the Civil Rights Movement, 1954-1965. Univ. Press of Mississippi, 2009.

Huda, Nor. Islam Nusantara: sejarah sosial intelektual Islam di Indonesia. Ar-Ruzz Media, 2007.

Karomi, Kholid. "Tuhan dalam Mistik Islam Kejawen (Kajian atas Pemikiran Raden Ngabehi Ranggawarsita).” Kalimah 11, no. $2 \quad$ (2013): 287. https://doi.org/10.21111/klm.v11i2.97. 
Ranggawarsita dan Sufisme Jawa: Studi Pemikiran Bagus Burham,...

Kholil, Ahmad. "ISLAM JAWA: Sufisme dalam Tradisi dan Etika Jawa." El Harakah 9, no. 2 (2007): 87.

Koentjaraningrat. Javanese Culture. 2. impr. Singapore: Oxford Univ. Pr, 1990.

Krippendorff, Klaus. Analisis isi: pengantar teori dan metodologi. Rajawali Pers, 1980.

Mahmudi. Wirid mistik Hidayat Jati: mutiara pemikiran teologi Islam kejawen. Pura Pustaka, 2005.

Mukaffa, Zumrotul. "The Era of Uncertainty and Ethical Arrangement in Javanese Classical Texts: Disseminating Ranggawarsita's Works as Source of Islamic Ethics in Islamic Higher Education.” Al-Jami'ab: Journal of Islamic Studies 56, no. 2 (18 Desember 2018): 461-93. https://doi.org/10.14421/ajis.2018.562.461-493.

Nata, Abuddin. Akblak tasamuf. Jakarta: Rajawali Pers, 2010.

Nordholt, Henk Schulte, Bambang Purwanto, dan Ratna Saptari. Perspektif baru penulisan sejarah Indonesia. Yayasan Obor Indonesia, 2008.

Pendahuluan, A. “( Sebuah Perbandingan Antara Sufisme Dan Kebatinan ) Muhammad Luthfi Ubaidillah ( Staf Ahli Bidang Penelitian dan Pengabdian Masyarakat Kemenag RI ) Abstrak Hakikat manusia menjadi suatu kajian yang selalu menarik untuk diperbincangkan di berbagai budaya ," t.t., 145-59.

Prasadana, Afrizal, dan Purwanto Purwanto. "Representasi Nilai Kearifan Ranggawarsita pada Kepemimpinan Kepala Dinas Penerangan Komando Armada II dalam Mewujudkan World Class Navy." representamen 6, no. 01 (2020).

Purwadi. Mistik kejawen pujangga Ronggowarsito. Media Abadi, 2005. Ramalan zaman edan Ronggowarsito. Media Abadi, 2004.

Ronggowarsito, R. Ng. Zaman edan. Narasi, 2017.

Setyawan, Bagus Wahyu. "Kajian Pragmatik Mengenai Tindak Tutur Direktif dalam Serat Joko Lodhang Karangan Raden Ngabehi Ranggawarsita." Jalabahasa: Jurnal Ilmiah Kebahasaan 14, no. 2 (2018): 67-79.

Shihab, Alwi. Islam sufistik: "Islam pertama” dan pengarubnya hingga kini di Indonesia. Mizan, 2001.

Simuh. Mistik Islam kejawen Raden Ngabehi Ranggawarsita: suatu studi terhadap serat Wirid Hidayat Jati. Penerbit Universitas Indonesia, 1988.

Sjamsuddin, Helius. Metodologi Sejarah. Ombak, 2007.

Soebardi. "Raden Ngabehi Jasadipura I, Court Poet of Surakarta: His Life and Works." Indonesia, no. 8 (1969): 81-102. https://doi.org/10.2307/3350670.

Syafrizal, Achmad. "Sejarah Islam Nusantara." Islamuna: Jumal Studi Islam 2, no. 2 (5 Desember 2015): 235-53. https://doi.org/10.19105/islamuna.v2i2.664. 
Samudra Eka Cipta

Ubaidilah, Muhammad Luthfi. "Konsep Ibn Al-'Arabĭ Dan Ranggawarsita Tentang Manusia (Sebuah Perbandingan Antara Sufisme Dan Kebatinan)." Misykah : Jurnal LPPM LAI BBC 1, no. 1 (18 Oktober 2017): 145-59. http://journal.bungabangsacirebon.ac.id/index.php/misykah/article/view/12.

Ushuluddin, Fakultas. "Konsep keadilan dalam serat kalatidha karya raden ngabehi ranggawarsita," 2014.

Wildemuth, Barbara M. Applications of social research methods to questions in information and library science. Westport, Conn: Libraries Unlimited, 2009.

Zed, Mestika. Metode penelitian kepustakaan. Ed. 2. Jakarta: Yayasan Obor Indonesia, 2008. 